\title{
Cross-Talk between Macrophage Migration Inhibitory Factor and Eotaxin in Allergic Eosinophil Activation Forms Leukotriene $\mathrm{C}_{\mathbf{4}}$-Synthesizing Lipid Bodies
}

\author{
Adriana Vieira-de-Abreu ${ }^{1}$, Andrea S. Calheiros ${ }^{1}$, Fabio P. Mesquita-Santos ${ }^{1,3}$, Elisabeth S. Magalhães ${ }^{2}$, \\ Diego Mourão-Sá ${ }^{2}$, Hugo C. Castro-Faria-Neto ${ }^{1}$, Marcelo T. Bozza ${ }^{2}$, Christianne Bandeira-Melo ${ }^{3 *}$ and \\ Patricia T. Bozza ${ }^{1 *}$
}

\begin{abstract}
${ }^{1}$ Laboratório de Imunofarmacologia, Instituto Oswaldo Cruz, Fundação Oswaldo Cruz, Rio de Janeiro, Brazil; and ${ }^{2}$ Departamento de Imunologia, Instituto de Microbiologia, and ${ }^{3}$ Laboratório de Inflamação, Instituto de Biofísica Carlos Chagas Filho, Universidade Federal do Rio de Janeiro, Rio de Janeiro, Brazil
\end{abstract}

\begin{abstract}
Recent studies have demonstrated an essential and nonredundant role for macrophage migration inhibitory factor (MIF) in asthma pathogenesis. Here we investigate the mechanisms involved in MIFinduced eosinophil activation. By using a model of allergic pulmonary inflammation, we observed that allergen challenge-elicited eosinophil influx, lipid body (also known as lipid droplets) biogenesis, and leukotriene (LT) $\mathrm{C}_{4}$ synthesis are markedly reduced in $\mathrm{Mif}^{-1-}$ compared with wild-type mice. Likewise, in vivo administration of MIF induced formation of new lipid bodies within eosinophils recruited to the inflammatory reaction site that corresponded to the intracellular compartment of increased LTC $_{4}$ synthesis. MIF-mediated eosinophil activation was at least in part due to a direct effect on eosinophils, because MIF was able to elicit lipid body assembly within human eosinophils in vitro, a phenomenon that was blocked by neutralization of the MIF receptor, CD74. MIF-induced eosinophil lipid body biogenesis, both in vivo and in vitro, was dependent on the cooperation of MIF and eotaxin acting in a positive-feedback loop, because anti-eotaxin and anti-CCR3 antibodies inhibit MIF-elicited lipid body formation, whereas eotaxin-induced lipid body formation is affected by anti-CD74 and MIF expression deficiency. Therefore, allergy-elicited inflammatory MIF acts in concert with eotaxin as a key activator of eosinophils

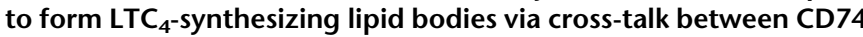
and CCR3. Due to the effect of MIF on eosinophils, strategies that inhibit MIF activity might be of therapeutic value in controlling allergic inflammation.
\end{abstract}

Keywords: macrophage migration inhibitory factor; leukotriene $\mathrm{C}_{4}$; lipid droplets; allergic inflammation; asthma

Macrophage migration inhibitory factor (MIF) is a pleiotropic molecule that acts as a critical mediator of both innate and acquired immune responses $(1,2)$. Recently, a role for MIF in pathogenesis of $\mathrm{T}$ helper (Th) type 2-driven inflammatory reactions was reported. A central, nonredundant function of MIF in asthma pathogenesis was established using Th2-driven animal models of allergic pulmonary inflammation, where

(Received in original form January 1, 2010 and in final form April 6, 2010)

*These authors contributed equally to the work.

This work was supported by Conselho Nacional de Desenvolvimento Científico e Tecnológico (Brazil), Fundação de Amparo à Pesquisa do Rio de Janeiro (Brazil), and Programa Núcleos de Excelência (PRONEX). The funding organizations had no role in design of the study, data collection or analysis, the decision to publish, or preparation of the manuscript.

Correspondence and requests for reprints should be addressed to Patricia T. Bozza, M.D., Ph.D., Laboratório de Imunofarmacologia, Instituto Oswaldo Cruz, Fundação Oswaldo Cruz, Avenue Brasil 4365, Manguinhos, Rio de Janeiro, RJ, 21045-900 Brazil. E-mail: pbozza@ioc.fiocruz.br

Am J Respir Cell Mol Biol Vol 44. pp 509-516, 2011

Originally Published in Press as DOI: 10.1165/rcmb.2010-0004OC on June 10, 2010

Internet address: www.atsjournals.org

\section{CLINICAL RELEVANCE}

We demonstrated a cooperative stimulatory loop between macrophage migration inhibitory factor (MIF) and eotaxin in allergy-elicited eosinophil activation, placing MIF as an interesting candidate for new antiallergic therapeutical development.

endogenous MIF was found to regulate bronchial hyperresponsiveness, mucus secretion, and eosinophilic inflammation (3-5). Supporting such a role in pulmonary inflammation, patients with asthma were found to have increased concentrations of MIF in the bronchoalveolar lavage (BAL) fluids, sputum, and sera $(6,7)$. Similarly, a role for MIF was also described in the Th2 response induced by parasitic infections, such as helminthic infections by Taenia crassiceps, Schistosoma japonicum, and Schistosoma mansoni (8-10).

Even though studies concur that MIF participates in the pathogenesis of Th2-driven diseases, such as asthma and parasitic infestations, the MIF-targeted mechanisms involved in regulation of $\mathrm{Th} 2$ pathologies are still incompletely understood. Although polarization toward a $\mathrm{Th} 2$ response was initially postulated as the targeted pathway, there is no consensus in the literature on this topic $(3-5,10)$. In regard to the development of Th2-driven disturbances, we hypothesized that MIF acts as a modulator of eosinophil activation. Indeed, MIF has emerged as a potent inflammatory mediator capable of regulating eosinophil differentiation and chemotaxis, as well as leukotriene (LT) $\mathrm{C}_{4}$ production triggered by allergic challenge $(3,10)$.

Eosinophil recruitment and subsequent activation at sites of allergic inflammation has the potential to generate and release diverse lipid and protein mediators critical to the development and perpetuation of the allergic process (11-13). Indeed, eosinophils represent a major source of $\mathrm{LTC}_{4}$ and its extracellular derivatives $\left(\mathrm{LTD}_{4}\right.$ and $\left.\mathrm{LTE}_{4}\right)$, products of the 5-lipoxygenase (5-LO) pathway of arachidonic acid metabolism in allergic diseases (14-16).

Central to the pathogenesis of allergic diseases, these cysteinyl LTs (cysLTs) cause bronchoconstriction, mucous hypersecretion, increased microvascular permeability, bronchial hyperresponsiveness, eosinophil infiltration, and airway remodeling (17-19). Although the enzymatic pathways by which eosinophils synthesize $\mathrm{LTC}_{4}$ are well established, the key regulatory mechanisms of allergen-induced $\mathrm{LTC}_{4}$ synthesis, such as its specialized intracellular compartmentalization and the relevant endogenous allergy-triggered stimuli, remain uncharacterized.

The formation of $\mathrm{LTC}_{4}$ requires the functional interaction of at least four proteins acting in cascade: cytoplasmic phospholi- 
pase $\mathrm{A}_{2}$; 5-LO-activating protein; 5-LO; and $\mathrm{LTC}_{4}$ synthase $(20,21)$. Studies from several groups suggest that dynamic compartmentalization of these biosynthetic proteins is a primary mechanism for the regulated synthesis of $\mathrm{LTC}_{4}$ (for review, see Refs. 22, 23). Upon leukocyte activation, three distinct intracellular domains may compartmentalize such macromolecular organization for $\mathrm{LTC}_{4}$ synthesis: the nuclear membrane (24); phagosomes (25); and/or lipid bodies (26).

Lipid bodies, also known as lipid droplets or adiposomes, are cytoplasmic lipid domains surrounded by a phospholipid monolayer with a unique fatty acid composition, characterized by a neutral lipid-rich core and variable protein composition $(27,28)$. Characterization of lipid body protein content in different cell types has suggested that lipid bodies are heterogeneous, dynamic, and multifunctional organelles. Proteins compartmentalized within lipid bodies include enzymes involved in lipid metabolism, cytokines, proteins of the Rab family, specific kinases, and small GTPases, thus positioning lipid bodies as potential regulators of lipid metabolism, membrane trafficking, and intracellular signaling (for review, see Refs. 28, 29). Likewise, by uncovering that eicosanoidforming enzymes are compartmentalized alongside esterified arachidonic acid within lipid bodies $(26,30,31)$, an additional lipid body function as inflammatory mediator producer was postulated. This was then confirmed by the direct detection of newly synthesized $\mathrm{LTC}_{4}$ in eosinophil lipid bodies $(32,33)$.

Lipid body biogenesis is a biological process that has been intensively studied over the past few years. Assembly of new lipid bodies is recognized as an acute, highly regulated cellular event that is stimulus and cell type specific, which takes place at specialized regions of endoplasmic reticulum, and ultimately determines the specific functions of the newly formed lipid bodies. Moreover, increased biogenic activity is a constant feature of leukocyte activation elicited by inflammatory process (for review, see Ref. 28), as observed in eosinophils from patients with Crohn's disease (34) and hypereosinophilic syndrome (35), and from animals undergoing allergic inflammation $(33,36,37)$.

Although it is recognized that the allergic inflammatory response increases the number of $\mathrm{LTC}_{4}$-synthesizing lipid bodies within activated eosinophils, the detailed molecular mechanisms controlling their biogenic process remain largely unclear. It was determined by in vitro assays that specific agonists, particularly eotaxin and prostaglandin $(\mathrm{PG}) \mathrm{D}_{2}$, could trigger signaling mechanisms that rapidly stimulate the formation of new LTC $_{4}$-synthesizing lipid bodies within human eosinophils $(32,33)$. Accordingly, in vivo studies conducted by our group showed that both the biogenesis of lipid bodies and the enhanced synthesis of $\mathrm{LTC}_{4}$ at newly formed lipid bodies triggered by allergic inflammation are partially mediated by eotaxin/regulated on activation, normal $\mathrm{T}$ cell-expressed and secreted (RANTES) acting via CCR3 receptors (33) and by $\mathrm{PGD}_{2}$ (37).

As discussed previously here, MIF mediated the enhancement of $\mathrm{LTC}_{4}$ production triggered by allergic challenge in a mouse asthma model (3). Therefore, we aimed to investigate the mechanisms involved in MIF-mediated, allergenelicited $\mathrm{LTC}_{4}$ synthesis, focusing on the ability of MIF to activate $\mathrm{LTC}_{4}$-synthesizing machinery in eosinophils by analyzing three key regulatory aspects: (1) the intracellular $\mathrm{LTC}_{4}$-synthesizing compartment; (2) the induced biogenesis of such cytoplasmic compartments, named lipid bodies; and (3) the potentially stimulatory cross-talk with eotaxin. Our results show that, at sites of eosinophilic inflammation, crosstalk between MIF and eotaxin activates eosinophils, and results in the assembly of lipid bodies with the ability to synthesize $\mathrm{LTC}_{4}$.

\section{MATERIAL AND METHODS}

\section{Reagents}

Chicken egg ovalbumin (OVA), BSA, PBS, 1-ethyl-3-(3dimethylamino-propyl) carbodiimide (EDAC), and mouse IgG1 were purchased from Sigma Chemical Co. (St. Louis, MO). Neutralizing antibodies (Abs) to murine and human eotaxin, recombinant murine (rm)MIF, rmeotaxin, rheotaxin, recombinant human (rh)MIF, and CCR3 were purchased from R\&D Systems (Minneapolis, MN), whereas anti-CD74 (clone LN2) was from BD Pharmimgen (San Diego, CA). MK 886 was purchased from Biomol (Plymouth Meeting, PA).

\section{Animals}

$\mathrm{C} 3 \mathrm{H} / \mathrm{He}, \mathrm{C} 3 \mathrm{H} / \mathrm{HeJ}, \mathrm{BALB} / \mathrm{c}$, and MIF-deficient $\left(\mathrm{Mif}^{-/-}\right)$mice $(3,38)$ (BALB/c background) ranging from 6 to 8 weeks old, of both sexes, were obtained from the Oswaldo Cruz Foundation breeding unit (Rio de Janeiro, Brazil). Protocols were approved by the Fundação Oswaldo Cruz animal welfare committee.

\section{Model of Allergic Pulmonary Eosinophilia}

Allergic inflammation in the lungs of actively sensitized mice was generated as previously described (2). Briefly, mice were sensitized with intraperitoneal injection of OVA $(10 \mu \mathrm{g} / \mathrm{mouse})$ and $\mathrm{Al}(\mathrm{OH}) 3(10 \mathrm{mg} / \mathrm{ml})$ resuspended in sterile saline $(0.2 \mathrm{ml})$ on Days 1 and 10. From Day 19 to Day 24 after sensitization, mice were challenged daily for 20 minutes with OVA $(5 \%$ in sterile saline) by aerosol. Sterile saline was aerosolized to sensitized mice as a negative control. Aerosolization was performed in a $30 \times 20 \times 10-\mathrm{cm}$ acrylic chamber, and the aerosol was generated with an ultrasonic nebulizer. At 24 hours after the last aerosolization, animals were killed by $\mathrm{CO}_{2}$ inhalation, and the tracheas were surgically exposed and cannulated. The BAL fluid was collected by washing the lungs with PBS (1 ml).

\section{Pleurisy Triggered by MIF or Eotaxin}

Naive mice received intrapleural injections of either rmMIF (0.1-1 $\mu \mathrm{g} /$ cavity) or rmeotaxin (30 pmol/cavity), each diluted in sterile saline immediately before use. Control animals were injected with the same volume $(0.1 \mathrm{ml})$ of saline. At 6 or 24 hours after stimulation, mice were killed by $\mathrm{CO}_{2}$ inhalation, and pleural cavities were rinsed with $1 \mathrm{ml}$ of PBS.

\section{Leukocyte Counts}

Total leukocytes (diluted with Turk's $2 \%$ acetic acid fluid) were counted using Neubauer chambers. Differential counts were performed in cytopins stained by the May-Grunwald-Giemsa method. Counts are reported as total number of eosinophils per BAL fluid or pleural cavity.

\section{Quantification of cysLTs and Eotaxin}

Amount of cysLTs found in BAL or pleural fluid were measured by a commercial EIA kit according to the manufacturer's instructions (Cayman Chemicals, Ann Arbor, MI). Eotaxin were measured in the pleural fluid using commercially available ELISA kit according to the manufacturer's protocol (R\&D Systems).

\section{EicosaCell for $\mathrm{LTC}_{4}$ Immunolocalization}

$\mathrm{LTC}_{4}$ was localized to the sites of formation, as previously described $(32,33)$. Briefly, leukocytes were recovered from the 
pleural cavity 6 hours after MIF or saline administration, and 1 hour after zileuton, by washing the cavity with $500 \mu \mathrm{l}$ of Hanks' balanced salt solution (HBSS). Cells were then immediately mixed with $500 \mu \mathrm{l}$ of EDAC (1\% in HBSS), which is used to cross-link eicosanoid carboxyl groups to amines of adjacent proteins. After a 30 -minute incubation at $37^{\circ} \mathrm{C}$ with EDAC to promote both cell fixation and permeabilization, pleural leukocytes were then washed with HBSS, cytospun onto glass slides, and blocked with HBSS containing $2 \%$ normal mouse serum and normal goat serum for 10 minutes. The cells were then incubated with rabbit anti-LTC 4 Abs (Cayman Chemicals) or nonimmune rabbit IgG for 45 minutes. The anti-adipose differentiation-related protein $\mathrm{Ab}$ was added for 45 minutes to distinguish cytoplasmic lipid bodies within leukocytes. Cells were washed three times with HBSS for 10 minutes and incubated with Cy2-labeled anti-rabbit IgG in addition to Cy3labeled anti-guinea pig secondary Abs for 1 hour. The slides were analyzed by confocal laser scanning microscopy on a Zeiss LSM 510-META (Jena, Germany).

\section{Isolation and Stimulation of Human Eosinophils}

Peripheral blood was obtained with informed consent from normal donors, and eosinophils were isolated by negative selection using the StemSep system (StemCell Technologies Inc., Vancouver, Canada). resulting in a final population that was more than $99 \%$ pure and more than $95 \%$ viable (39). The protocol used was approved by the Fundação Oswaldo Cruz ethics review board. Purified eosinophils $\left(2 \times 10^{6}\right.$ cells $/ \mathrm{ml}$ in $\left.\mathrm{HBSS}^{-1-}\right)$ were incubated for 1 hour in a water bath $\left(37^{\circ} \mathrm{C}\right)$ with rhMIF $(0.05-5 \mathrm{ng} / \mathrm{ml})$, rheotaxin $(1-100 \mathrm{ng} / \mathrm{ml})$, or a combination of MIF $(0.05 \mathrm{ng} / \mathrm{ml})$ and eotaxin $(1 \mathrm{ng} / \mathrm{ml})$. Each in vitro
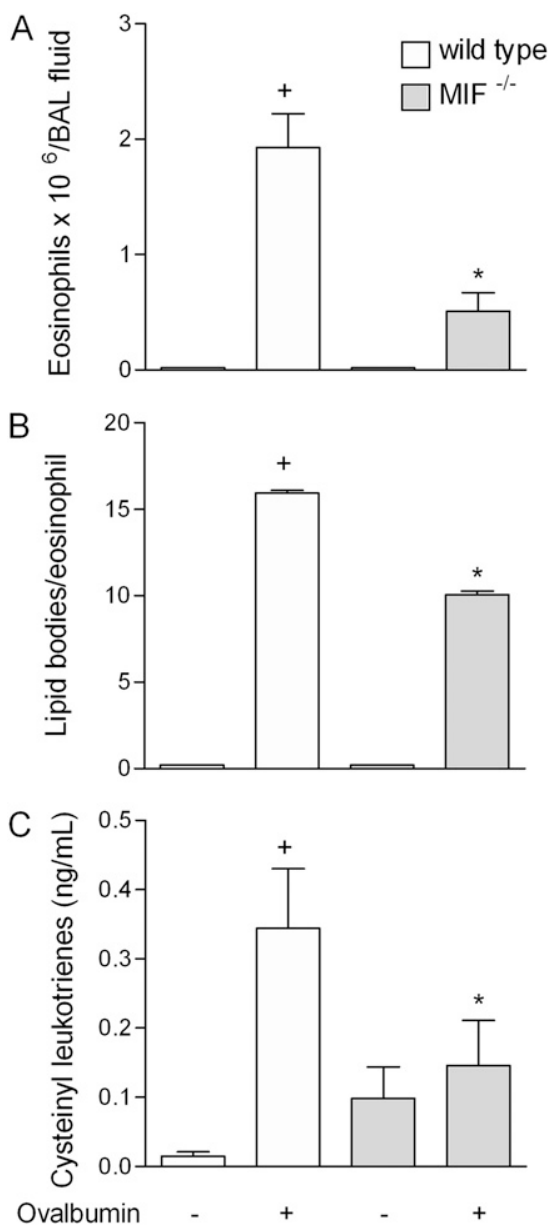

experiment was performed in triplicate and repeated at least three times, with eosinophils purified from different donors.

\section{Lipid Body Staining and Enumeration}

To quantify lipid bodies, eosinophils were cytocentrifuged (450 rpm, $5 \mathrm{~min}$ ) onto glass slides., While still moist, cells were fixed in $3.7 \%$ formaldehyde (diluted in $\mathrm{Ca}^{2+} / \mathrm{Mg}^{2+}$-free HBSS [pH $7.4]$ ), rinsed in $0.1 \mathrm{M}$ cacodylate buffer ( $\mathrm{pH} 7.4$ ), stained with $1.5 \% \mathrm{OsO}_{4}$ for 30 minutes, rinsed in distilled $\mathrm{H}_{2} \mathrm{O}$, immersed in $1.0 \%$ thiocarbohydrazide for 5 minutes, rinsed in $0.1 \mathrm{M}$ cacodylate buffer, restained with $1.5 \% \mathrm{OsO}_{4}$ for 3 minutes, rinsed in distilled water, and then dried and mounted. Cell morphology was observed and lipid bodies were quantified by microscopy. A total of 50 consecutively scanned eosinophils was then subjected to blinded evaluation by more than one individual. Results are expressed as the number of lipid bodies per eosinophil.

\section{Treatments}

Using the pleurisy model, animals were pretreated with intrapleural injections of anti-murine eotaxin monoclonal $\mathrm{Ab}(\mathrm{mAb})$ (10 $\mu \mathrm{g} /$ cavity) 30 minutes before allergic challenge. Animals pretreated with an irrelevant Ab showed no alteration of MIFinduced response (data not shown).

For in vitro mechanistic studies, eosinophils were pretreated for 30 minutes with $10 \mu \mathrm{g} / \mathrm{ml}$ of neutralizing Abs against human CD74 (clone LN2, as described in Ref. 40), eotaxin, or CCR3. Isotype-matched nonimmune Abs were used as controls. The anti-CD74 Ab has azide; however, at the concentrations used (final concentration $\leqslant 0.002 \%$ ) it did not affected viability $(>95 \%)$ or lipid body formation.

A

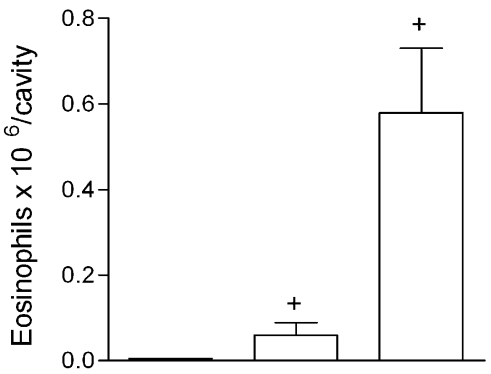

B

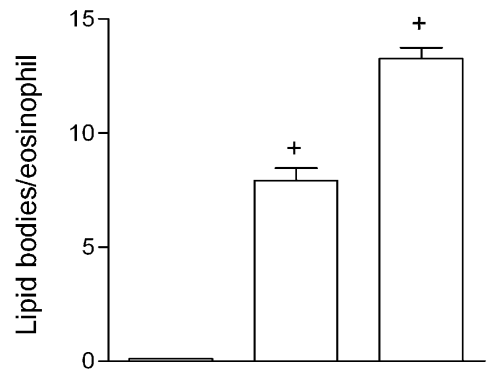

sults are expressed as the mean ( \pm SEM) calculated from at least eight animals. ${ }^{+} p \leqslant$ 0.05 compared with saline control group; $* P \leqslant 0.05$ compared with wild-type (WT) stimulated mice.

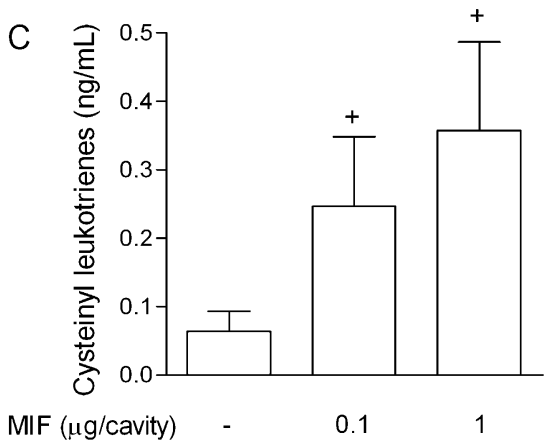

Figure 2. MIF evokes eosinophil influx $(A)$, lipid body formation within recruited eosinophils (B), and cysLT synthesis $(C)$ in a pleurisy model. Analysis was performed on pleural fluids harvested 24 hours after intrapleural injection of recombinant murine MIF (0.1 and $1 \mu \mathrm{g} /$ cavity). The control group was injected with sterile saline. Results are expressed as the mean ( \pm SEM) calculated from at least eight animals. ${ }^{+} p \leqslant$ 0.05 compared with control group. 
TABLE 1. IN VIVO EFFECTS OF MACROPHAGE MIGRATION INHIBITORY FACTOR ON EOSINOPHIL INFLUX AND LIPID BODY BIOGENESIS ARE NOT DUE LPS CONTAMINATION, BECAUSE ACTIVATION OF TOLL-LIKE RECEPTOR 4 IS NOT INVOLVED IN THESE PHENOMENA

\begin{tabular}{lccc}
\hline Condition & Animal Strain & Eosinophils/Cavity & Lipid Bodies/Cell \\
\hline Saline & $\mathrm{C} 3 \mathrm{H} / \mathrm{He}$ & $0.01 \pm 0.01$ & $0.50 \pm 0.01$ \\
rmMIF & $\mathrm{C} 3 \mathrm{H} / \mathrm{He}$ & $0.18 \pm 0.05^{*}$ & $4.54 \pm 0.05^{*}$ \\
Saline & $\mathrm{C} 3 \mathrm{H} / \mathrm{HeJ}$ & $0.01 \pm 0.01$ & $0.20 \pm 0.01$ \\
rmMIF & $\mathrm{C} 3 \mathrm{H} / \mathrm{HeJ}$ & $0.16 \pm 0.03^{*}$ & $4.08 \pm 0.05^{*}$ \\
\hline
\end{tabular}

Definition of abbreviation: rmMIF, recombinant murine macrophage migration inhibitory factor.

Toll-like receptor 4-sensitive $(\mathrm{C} 3 \mathrm{H} / \mathrm{HeN})$ and nonsensitive $(\mathrm{C} 3 \mathrm{H} / \mathrm{HeJ})$ mice were stimulated in vivo with rmMIF (1 $\mu \mathrm{g} /$ cavity) for 24 hours. Results are expressed as means ( \pm SEM) calculated from at least six distinct animals.

* $P \leqslant 0.01$ compared to saline-stimulated cells.

\section{Statistical Analysis}

Results from in vivo assays are expressed as means $( \pm$ SEM), and were analyzed statistically by means of ANOVA, followed by the Newman-Keuls Student test, with the level of significance set at a $P$ value less than 0.05 .

\section{RESULTS}

MIF Mediates Assembly of Eosinophil Lipid Bodies and Synthesis of $\mathrm{LTC}_{4}$ Triggered by Allergic Pulmonary Inflammation

We have previously reported that, in addition to the well known induction of $\mathrm{LTC}_{4}$ production, allergic challenge also triggers the biogenesis of lipid bodies, which function as intracellular compartments for $\mathrm{LTC}_{4}$ synthesis within recruited eosinophils (33). The mechanisms involved in eliciting the biogenesis of cytoplasmic lipid bodies and priming infiltrating eosinophils for enhanced $\mathrm{LTC}_{4}$ production in allergic inflammatory sites are not completely known, but involve, at least, the mediation by eotaxin and $\mathrm{PGD}_{2}$, two well known eosinophilotactic agents $(33,37)$.
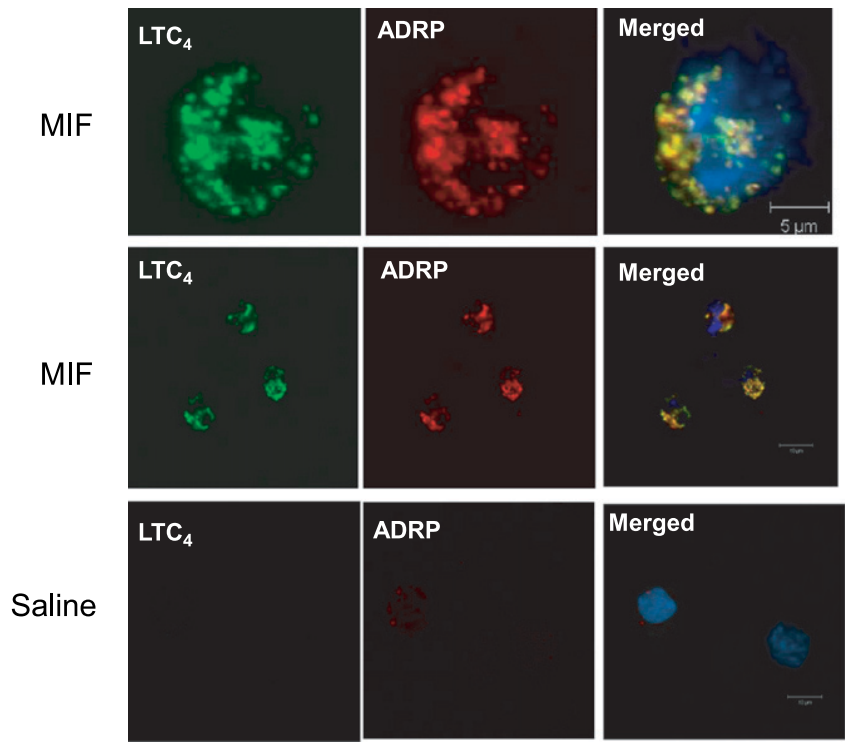

Figure 3. Eosinophil $\mathrm{LTC}_{4}$ synthesis in MIF-stimulated animals occurs in lipid bodies. EicosaCell images illustrate intracellular immunodetection of newly formed $\mathrm{LTC}_{4}$ (green) and adipose differentiation-related protein (ADRP) (red) in cells from MIF-stimulated (upper and middle panels) and saline-stimulated animals (lower panels). Overlaid immunofluorescence microscopy images of identical fields are shown in the right column.
Recently, we and others have identified MIF as a key mediator of allergic inflammation $(3-5,28)$. Here, to investigate whether MIF has any role in eosinophil lipid body-driven $\mathrm{LTC}_{4}$ synthesis triggered by allergic challenge, a model of acute allergic pulmonary inflammation in wild-type (WT) versus Mif $^{-/-}$mice (BALB/c background) was used. As previously demonstrated (3) and shown in Figure 1A, BAL eosinophilia triggered by aerosol allergic challenge is drastically reduced in $\mathrm{MIF}^{-1-}$ mice compared with the response observed in WT mice. Similarly, both formation of new lipid bodies within recruited eosinophil and cysLT generation were significantly decreased in allergenchallenged $\mathrm{MIF}^{-1-}$ mice when compared with WT mice (Figures $1 \mathrm{~B}$ and $1 \mathrm{C}$ ). Together, these data indicate that endogenous MIF, found at an allergic inflammatory site is capable of eliciting lipid body assembly within infiltrating eosinophils, in parallel to enhancing the production of cysLTs.

\section{MIF Triggers In Vivo Biogenesis of Functional}

\section{LTC $_{4}$-Synthesizing Lipid Bodies within Recruited Eosinophils}

Because MIF appears to contribute to eosinophil activation during allergic responses, we examined whether MIF was able to elicit eosinophil $\mathrm{LTC}_{4}$-synthesizing machinery in recruited eosinophils in vivo. Intrapleural administration of MIF (0.1 or $1 \mu \mathrm{g} /$ cavity) in naive mice induced accumulation of eosinophils
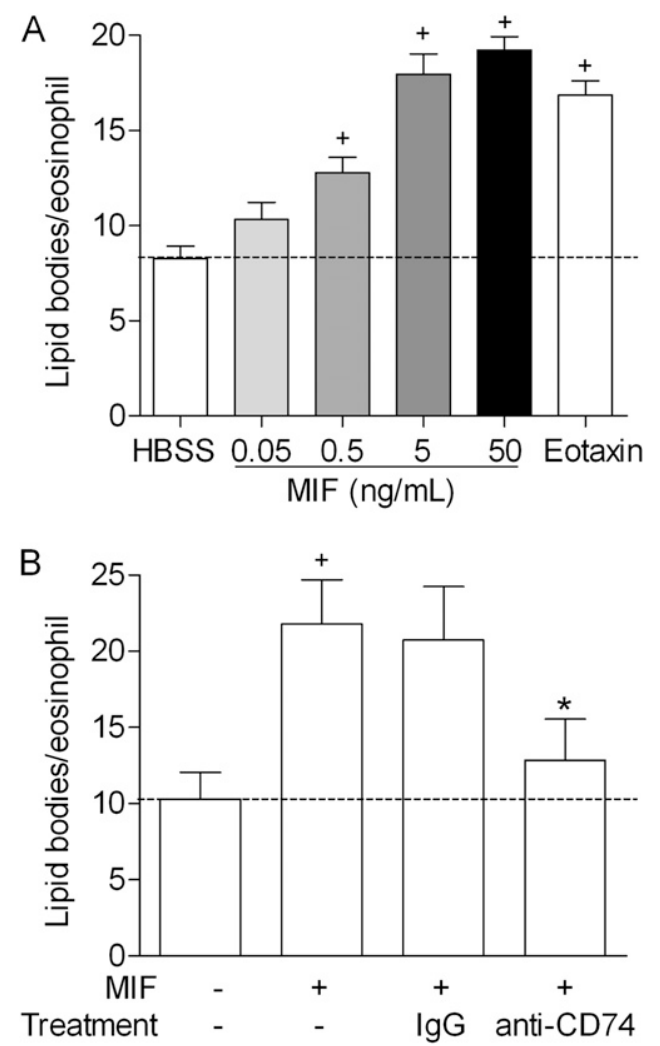

Figure 4. MIF induces lipid body biogenesis in human eosinophils in vitro. $(A)$ Dose-dependent response of recombinant human (rh)MIF (from 0.05 to $50 \mathrm{ng} / \mathrm{ml}$ ) on lipid body biogenesis after stimulation of human eosinophils in vitro for 1 hour. (B) Effect of 30-minute pretreatment with anti-CD74 or isotype control IgG1 on rhMIF-stimulated $(50 \mathrm{ng} / \mathrm{ml})$ human eosinophils. Results are expressed as means ( \pm SEM) calculated from triplicate results from one donor, and are representative of results from eosinophils isolated from at least three distinct donors. ${ }^{+} p \leqslant 0.05$ compared with Hanks' balanced salt solution (HBSS) control group; ${ }^{*} P \leqslant 0.05$ compared with MIF-stimulated untreated cells. 
in a dose-dependent manner (Figure 2A). These eosinophils showed an increased number of cytoplasmic lipid bodies (Figure $2 \mathrm{~B}$ ), thereby demonstrating the ability of MIF to activate the formation of lipid body biogenesis machinery in vivo. Of note, MIF-induced eosinophil activation in vivo was not dependent on LPS contamination, because $\mathrm{C} 3 \mathrm{H} / \mathrm{HeJ}$ mice, an LPS-hyporesponsive strain that has an inactivating point mutation within the signal-transducing domain of Toll-like receptor 4 (41), also respond to intrapleural MIF ( $1 \mu \mathrm{g} /$ cavity) with eosinophil recruitment and lipid body formation of similar magnitudes to those observed in $\mathrm{C} 3 \mathrm{H} / \mathrm{HeN}$ mice, which express functional Toll-like receptor 4 (Table 1).

As in allergic inflammation, and concurring with MIFinduced in vivo lipid body biogenesis, there was also significant production of cysLTs in MIF-injected animals (Figure 2C). It was determined that this parallel increase in numbers of lipid bodies and levels of secreted cysLTs was the result of a functional relationship between lipid bodies and cysLTs. As illustrated in Figure 3, EicosaCell, a methodology that cross-links and immunolabels $\mathrm{LTC}_{4}$ at the original sites of synthesis, identified infiltrating eosinophils as the cell population responsible for $\mathrm{LTC}_{4}$ production during MIF-elicited inflammatory reactions. In addition, a more detailed analysis revealed that the intracellular $\mathrm{LTC}_{4}$-synthesizing compartment displayed a punctate cytoplasmic pattern proximal to, but separate from, the nucleus, which is fully consistent in size and form with eosinophil lipid bodies. In fact, the compartmentalization of newly formed $\mathrm{LTC}_{4}$ in eosinophil lipid bodies was ascertained by the colocalization with adipose differentiation-related protein (Figure 3). Virtually no $\mathrm{LTC}_{4}$ was immunolocalized within cells of saline-injected or MIF-stimulated, MK886-treated animals (data not shown), thus demonstrating that the newly formed lipid bodies of in vivo, MIF-stimulated eosinophils are enzymatically suited for effective $\mathrm{LTC}_{4}$ synthesis.

\section{MIF Activates Eosinophils Directly through Its Receptor, CD74}

To investigate whether MIF was indeed capable to directly activating eosinophils and sufficient to trigger the formation of new lipid bodies, we stimulated in vitro purified human eosin- ophils with rhMIF. Figure 4A shows that rhMIF $(0.05-50 \mathrm{ng} / \mathrm{ml})$ induced a rapid $(1 \mathrm{~h})$ and dose-dependent increase in the numbers of cytoplasmic lipid bodies within human eosinophils isolated from healthy donors. Moreover, rhMIF-induced lipid body biogenesis appeared to be a direct effect of MIF on specific receptors expressed on eosinophil surface, because the neutralizing $\mathrm{Ab}$ against $\mathrm{CD} 74$, which recognizes the major histocompatibility complex class II invariant chain identified as the MIF receptor (40), significantly inhibited the effects of MIF. Together, this indicates that eosinophils respond directly to MIF stimulation, which, at least in part, depends on CD74 binding. Eosinophils pretreated with isotype-matched, nonimmune $\mathrm{Ab}$ displayed expected lipid body biogenesis under MIF stimulation (Figure 4 and data not shown). Moreover, the specificity of the treatment was confirmed by the observation that CD74 Ab neutralization failed to inhibit platelet activating factor (PAF)induced lipid body formation (from $19.8 \pm 1.6$ to $17.4 \pm 2.8$ lipid bodies/eosinophil; $n=3$ [when nontreated and anti-CD74treated, PAF-stimulated eosinophils were compared]).

\section{Eotaxin Mediates MIF-Driven Eosinophil Activation}

The mechanisms involved in MIF-induced lipid body formation were further investigated by focusing on the putative cross-talk between MIF and eotaxin. It is well established that CCR3 activation by eotaxin in eosinophils stimulates both potent chemoattractant and lipid body biogenic responses, which control allergen-driven $\mathrm{LTC}_{4}$-synthesizing machinery (for review, see Ref. 32). Here, several of our findings show that MIF-induced eosinophil activation, both in vivo and in vitro, appeared to be dependent on eotaxin-driven autocrine and/or paracrine activity: (1) as shown in Figure 5A, in vivo pretreatment with a neutralizing anti-murine eotaxin mAb significantly inhibited both eosinophil influx and lipid body biogenesis induced by the i.pl. administration of rMIF; (2) increased levels of eotaxin were found in the pleural fluid of mice injected with MIF (1 $\mu \mathrm{g} /$ cavity) (Figure $5 \mathrm{~B}$ ); and (3) in vitro rMIF-elicited, CD74-dependent lipid body assembly within human eosinophils was blocked by neutralizing antihuman eotaxin $\mathrm{mAb}$, and is significantly inhibited by anti-
A
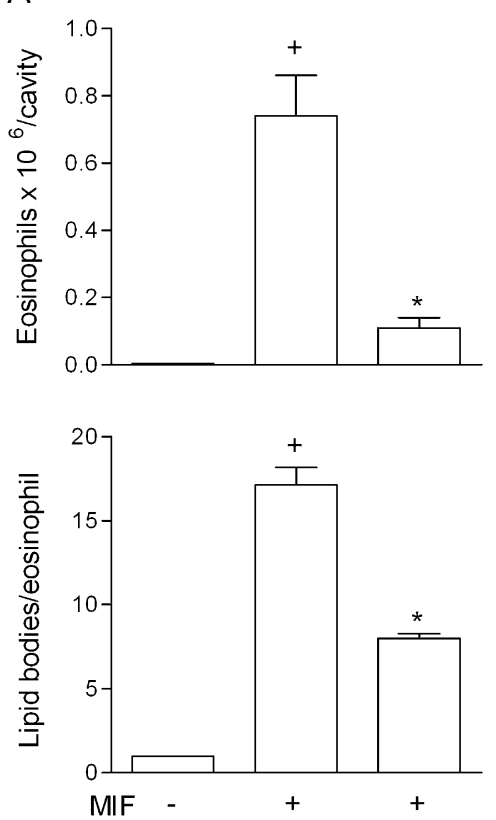

Treatment
B

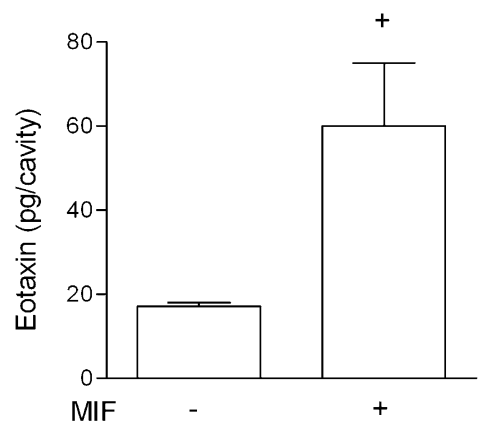

C

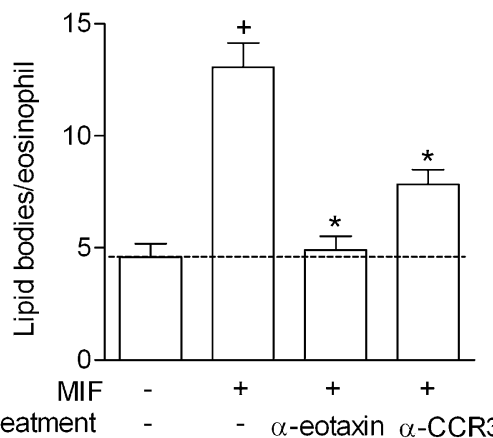

Figure 5. Role of eotaxin in MIF-driven eosinophil activation. (A) Mice received an intrapleural injection of recombinat murine ( $\mathrm{rm}$ )MIF ( $1 \mu \mathrm{g} /$ cavity). Analysis of eosinophil influx and lipid body formation were performed 24 hours after MIF administration. $(B)$ Pleural levels of eotaxin were analyzed 6 hours after rmMIF i.pl. injection ( $1 \mu \mathrm{g} /$ cavity). Results are expressed as the mean ( \pm SEM) calculated from at least six animals. ${ }^{+} P \leqslant 0.05$ compared with control animals; ${ }^{*} P \leqslant 0.05$ compared with rmMIF-injected mice. For in vitro analysis of lipid body biogenesis shown in (C), purified human eosinophils were preincubated with anti-eotaxin or anti-CCR3 and then stimulated with $\mathrm{rhMIF}(5 \mathrm{ng} / \mathrm{ml})$ for 1 hour. In vitro results are expressed as means ( \pm SEM) calculated from triplicate results from one donor, and are representative of results from eosinophils isolated from at least three distinct donors. ${ }^{+} P \leqslant 0.05$ compared with HBSS control group; ${ }^{*} P \leqslant$ 0.05 compared with MIF-stimulated, untreated cells. 
human CCR3 mAb (Figure 5C), suggesting that an endogenous eosinophil-derived eotaxin found at the site of the inflammatory reaction could mediate part of the MIF/CD74-induced eosinophil activation response.

\section{MIF Mediates Eotaxin-Driven Eosinophil Activation}

To better characterize the role of MIF and eotaxin cross-talk on regulating eosinophil responses, the input of $\mathrm{MIF} / \mathrm{CD} 74$ on eotaxin-induced eosinophil activation was evaluated. Similar to the MIF-triggered eosinophil activation response mediated by eotaxin, MIF autocrine/paracrine activity appears to mediate the ability of eotaxin to trigger lipid body biogenesis. Although $\mathrm{Mif}^{-1-}$ mice stimulated with eotaxin (30 pmol/cavity, i.pl.) in vivo showed eosinophil influx levels comparable to WT mice, $\mathrm{Mif}^{-/-}$mice displayed negligible eosinophil lipid body biogenesis after eotaxin stimulation (Figure 6). This result was confirmed when in vitro neutralization of human CD74 on human eosinophils was able to inhibit lipid body formation triggered by rheotaxin (Figure 7A), indicating that eotaxinstimulated eosinophils rapidly secrete MIF that, acting autocrinally and/or paracrinally on CD74 expressed on eosinophils, triggers assembly of new lipid bodies. Finally, as shown in Figure $7 \mathrm{~B}$, suboptimal concentrations of rheotaxin $(1 \mathrm{ng} / \mathrm{ml})$ and $\mathrm{rhMIF}(0.05 \mathrm{ng} / \mathrm{ml})$ acted in a cooperative manner to induce assembly of new lipid bodies. Therefore, in addition to mediating eosinophil activation, physiological levels of eotaxin and MIF found in vivo at sites of eosinophilic inflammation may also synergize to effectively activate recruited eosinophils.
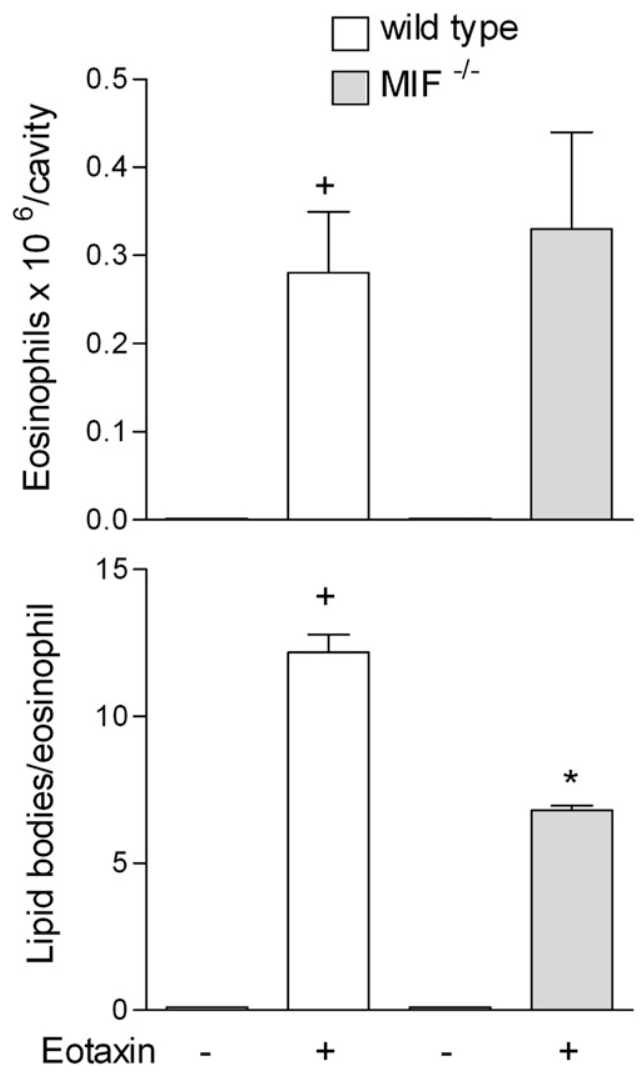

Figure 6. MIF mediates eotaxin-driven eosinophil activation. WT and $\mathrm{Mif}^{-1-}$ mice received an intrapleural injection of eotaxin (30 pmol/cavity). Analysis of eosinophil influx and lipid body formation were performed 24 hours after eotaxin administration. Results are expressed as the mean ( \pm SEM) calculated from at least six animals. $+P \leqslant 0.05$ compared with nonstimulated WT mice; ${ }^{*} P \leqslant 0.05$ compared with eotaxin-injected WT mice.
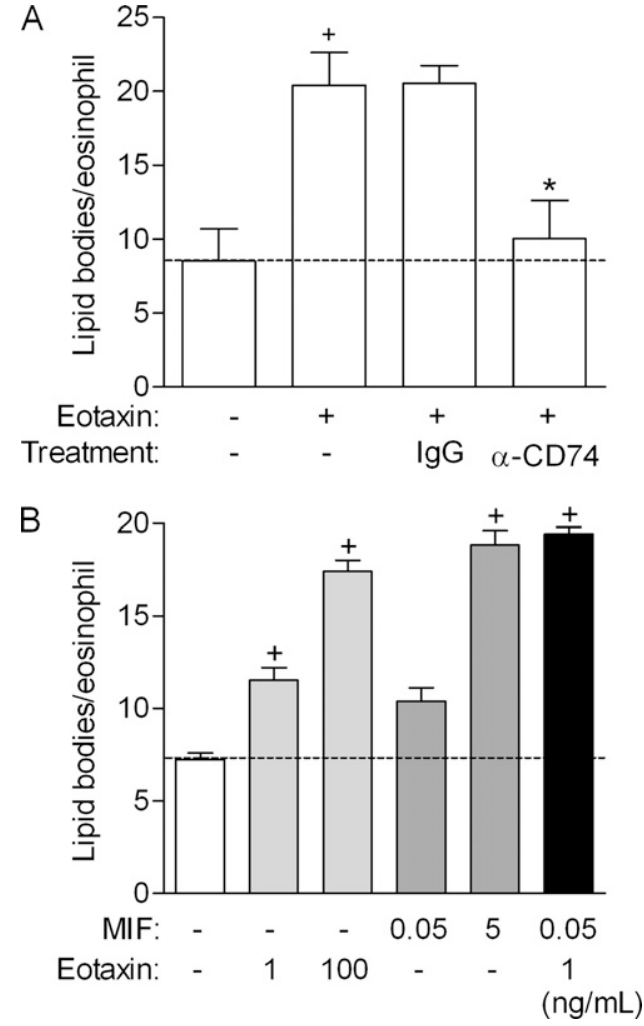

Figure 7. MIF mediates eotaxin-driven eosinophil activation in vitro. Lipid body formation in purified human eosinophils that were $(A)$ preincubated for 30 minutes with anti-CD74 or isotype control $\lg \mathrm{G} 1$, and then stimulated with eotaxin $(100 \mathrm{ng} / \mathrm{ml})$, or $(B)$ stimulated with recombinant human (rh)MIF (0.05 or $5 \mathrm{ng} / \mathrm{ml})$, eotaxin $(1$ or $100 \mathrm{ng} / \mathrm{ml}$ ), or costimulated with both eotaxin $(1 \mathrm{ng} / \mathrm{ml})$ and $\operatorname{rhMIF}(0.05 \mathrm{ng} / \mathrm{ml})$ in vitro. Analysis of lipid body formation was performed 1 hour after stimulation. Results are representative of three independent experiments. $+p \leqslant 0.05$ compared with HBSS control group; ${ }^{*} p \leqslant 0.05$ compared with eotaxin-stimulated, untreated cells.

\section{DISCUSSION}

Recent studies have demonstrated that MIF has an essential role in modulating several aspects of the physiopathology of allergic pulmonary inflammation, including eosinophil recruitment and the production of inflammatory mediators in the lung (3). In addition, it has been previously shown that MIF can activate distinct intracellular signaling pathways, which can enhance cell eicosanoid synthetic capacity $(42,43)$. Our study investigates the mechanisms involved in the interplay of MIF and cysLTs in allergic pulmonary inflammation, whereby MIF may directly activate and thereby enhance the capacity of eosinophils to synthesize $\mathrm{LTC}_{4}$. By employing in vivo and in vitro assays, we characterized the ability of MIF to directly activate eosinophils, eliciting rapid biogenesis of $\mathrm{LTC}_{4}$-synthesizing lipid bodies, organelles considered as markers of leukocyte activation. Moreover, we demonstrated that MIF functions via activation of its receptor, CD74, and acts in concert with eotaxin in a positive-feedback loop to activate eosinophils in response to allergic pulmonary inflammation.

Biogenesis of cytoplasmic lipid bodies has been noted within cells engaged in inflammatory disorders, and, although they were long viewed as lipid storage depots within cells, it has now become increasingly accepted that these organelles compartmentalize a diverse set of proteins and, therefore, participate in different cell functions, including eicosanoid synthesis (reviewed in Ref. 28). In regard to lipid bodies found in 
eosinophils, in vivo and in vitro studies conducted by our group have shown that an induced, highly orchestrated phenomenon, which is mediated, in part, by CCR3 activation induced by endogenously produced eotaxin and RANTES (32, 36), controls the biogenesis of eosinophil lipid bodies. These newly formed eosinophil lipid bodies are sites of 5-LO-driven $\mathrm{LTC}_{4}$ synthesis-which contributes to the characteristic enhancement of cysLTs production in response to allergic challenge (33). In this study, we found that MIF has, as with CCR3-activating chemokines, a potent and direct effect on eosinophils to stimulate lipid body biogenesis. Furthermore, the capacity of MIF to regulate lipid body assembly within infiltrating eosinophils during allergic pulmonary pathogenesis was found to impact the ability of eosinophils to generate $\mathrm{LTC}_{4}$, thereby contributing to enhanced cysLT generation in vivo.

The mechanisms involved in MIF-induced eosinophil activation, which culminates in biogenesis of $\mathrm{LTC}_{4}$-synthesizing lipid bodies, emerged as a two-player receptor engagement system. In regard to allergic inflammation, eosinophil-activating mediators, including PAF $(26,35)$, IL-5 $(35,44)$, CC chemokines (32), and $\mathrm{PGD}_{2}$ (37), act directly on receptors on the eosinophil surface and initiate intracellular signaling cascades that culminate with de novo formation of lipid bodies and prime $\mathrm{LTC}_{4}$ synthesis.

Recently, CD74, the cell surface form of the major histocompatibility complex class II-associated invariant chain, was demonstrated to be a high-affinity MIF receptor with signaltransducing ability (40). We observed a significant inhibition of MIF-induced lipid body formation in human eosinophils in vitro using neutralizing anti-human $\mathrm{mAb} C D 74$, suggesting that MIF directly activates eosinophils to form lipid bodies, in part by interacting with its specific membrane receptor. Although MIF may have direct effects on eosinophils via CD74 activation, our results demonstrate that MIF cooperates with eotaxin to trigger robust eosinophil activation and form new lipid bodies.

We recently showed that endogenously generated eotaxin partially mediates allergen- and $\mathrm{PGD}_{2}$-induced formation of eosinophil lipid bodies $(36,37)$. Moreover, either exogenously administered MIF or endogenously generated MIF, in the course of allergic reaction, are able to elicit eotaxin generation (3). Complementary to this, we verified that inhibition of eotaxin or its receptor, CCR3, either in vivo or in vitro, substantially reduced MIF-triggered eosinophil lipid body formation. This suggests that part of the mechanism of MIF-induced lipid body formation is due to an indirect effect on CCR3 by eosinophil-derived eotaxin, which is rapidly released in response to MIF stimulation, and contributes to the process in an autocrine/paracrine manner. Of note, eotaxin-driven eosinophil lipid body biogenesis was also partially inhibited by blocking MIF and CD74, suggesting that MIF and eotaxin cooperate to fully activate eosinophils.

Together, our data, as illustrated in Figure 8, demonstrate that, during eosinophilic allergic reactions, MIF controls eosinophil activation by binding to its receptor, and triggers both $\mathrm{LTC}_{4}$ synthesis within newly formed lipid bodies as well as the rapid release of preformed eotaxin. In response, such an eosinophil-derived chemokine, acting paracrinally and/or autocrinally on eosinophils, binds to the CCR3 receptor to induce both lipid body-driven $\mathrm{LTC}_{4}$ synthesis and secretion of stored MIF from eosinophils. Therefore, after an initial increase of cell-free eotaxin and/or MIF concentrations within sites of allergic reaction, characterized by local eosinophilia, a system of eosinophil retroactivation appears to take place that results in lipid body-driven $\mathrm{LTC}_{4}$ production by infiltrating eosinophils. Importantly, among other cytokines, eosinophils are known to store preformed pools of both MIF and eotaxin

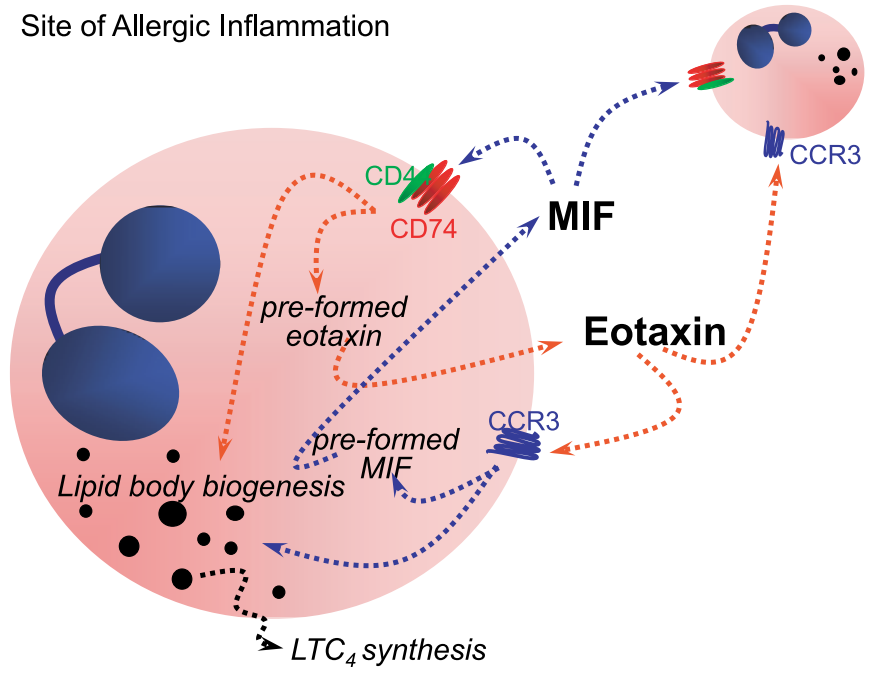

Figure 8. Cross-talk between MIF and eotaxin in regulating eosinophil activation. In sites of allergic inflammatory reactions, physiological concentrations of endogenous MIF and eotaxin (potentially derived from infiltrating eosinophils) act on their cognate receptors expressed on recruited eosinophils (CD74 and CCR3, respectively), and cooperate in an autocrine/paracrine fashion to elicit eosinophil activation, which is characterized by lipid body biogenesis and compartmentalized LTC $_{4}$ synthesis.

(reviewed in Ref. 45). Moreover, it is also recognized that properly stimulated eosinophils can rapidly select and secrete small, but biologically active amounts of eotaxin, which can function in an autocrine manner (39).

Eosinophil activation evoked by MIF launches the rapid, but highly regulated biogenic process of lipid body assembly, which forms organelles committed to synthesizing large amounts of $\mathrm{LTC}_{4}$, a typical result of allergic inflammatory responses. CysLTs are known to be an essential mediator of bronchial hyperresponsiveness, mucus secretion, the production of inflammatory mediators, and eosinophil recruitment-the same allergic features now recognized to be regulated, in part, by MIF. Our data also unveil a cross-talk mechanism between eosinophil-derived eotaxin and MIF that controls eosinophil activation and regulates the amplification of allergy-related $\mathrm{LTC}_{4}$ synthesis. Therefore, such MIF/eotaxin-elicited, eosinophil lipid body-driven $\mathrm{LTC}_{4}$ synthesis rises as an interesting candidate for new antiallergic therapeutic approaches.

Author Disclosure: None of the authors has a financial relationship with a commercial entity that has an interest in the subject of this manuscript.

Acknowledgments: The authors thank the Program for Technological Development in Tools for Health (PDTIS)/FIOCRUZ for use of its confocal laser scanning microscopy (CLSM) facility. The authors thank Bernardo Pascarelli for the assistance with CLSM analysis.

\section{References}

1. Baugh JA, Bucala R. Macrophage migration inhibitory factor. Crit Care Med 2002; 30(1, Suppl)S27-S35.

2. Calandra T, Roger T. Macrophage migration inhibitory factor: a regulator of innate immunity. Nat Rev Immunol 2003;3:791-800.

3. Magalhaes ES, Mourao-Sa DS, Vieira-de-Abreu A, Figueiredo RT, Pires AL, Farias-Filho FA, Fonseca BP, Viola JP, Metz C, Martins MA, et al. Macrophage migration inhibitory factor is essential for allergic asthma but not for Th2 differentiation. Eur J Immunol 2007;37:1097-1106.

4. Mizue Y, Ghani S, Leng L, McDonald C, Kong P, Baugh J, Lane SJ, Craft J, Nishihira J, Donnelly SC, et al. Role for macrophage migration inhibitory factor in asthma. Proc Natl Acad Sci USA 2005;102:14410-14415.

5. Kobayashi M, Nasuhara Y, Kamachi A, Tanino Y, Betsuyaku T, Yamaguchi E, Nishihira J, Nishimura M. Role of macrophage mi- 
gration inhibitory factor in ovalbumin-induced airway inflammation in rats. Eur Respir J 2006;27:726-734.

6. Rossi AG, Haslett C, Hirani N, Greening AP, Rahman I, Metz CN, Bucala R, Donnelly SC. Human circulating eosinophils secrete macrophage migration inhibitory factor (MIF): potential role in asthma. J Clin Invest 1998;101:2869-2874.

7. Yamaguchi E, Nishihira J, Shimizu T, Takahashi T, Kitashiro N, Hizawa N, Kamishima K, Kawakami Y. Macrophage migration inhibitory factor (MIF) in bronchial asthma. Clin Exp Allergy 2000;30:12441249.

8. Stavitsky AB, Metz C, Liu S, Xianli J, Bucala R. Blockade of macrophage migration inhibitory factor (MIF) in Schistosoma japonicuminfected mice results in an increased adult worm burden and reduced fecundity. Parasite Immunol 2003;25:369-374.

9. Rodriguez-Sosa M, Rosas LE, David JR, Bojalil R, Satoskar AR, Terrazas LI. Macrophage migration inhibitory factor plays a critical role in mediating protection against the helminth parasite taenia crassiceps. Infect Immun 2003;71:1247-1254.

10. Magalhães E, Paiva CN, Souza HS, Pyrrho AS, Mourão-Sá D, Figueiredo RT, Vieira-de-Abreu A, Dutra HS, Silveira MS, Gaspar-Elsas MI, et al. Macrophage migration inhibitory factor is critical to interleukin-5driven eosinophilopoiesis and tissue eosinophilia triggered by Schistosoma mansoni infection. FASEB J 2009;23:1262-1271.

11. Wardlaw AJ. Molecular basis for selective eosinophil trafficking in asthma: a multistep paradigm. J Allergy Clin Immunol 1999;104:917-926.

12. Gleich GJ. Mechanisms of eosinophil-associated inflammation. J Allergy Clin Immunol 2000;105:651-663.

13. Costa JJ, Weller PF, Galli SJ. The cells of the allergic response: mast cells, basophils, and eosinophils. JAMA 1997;278:1815-1822.

14. Weller PF, Lee CW, Foster DW, Corey EJ, Austen KF, Lewis RA. Generation and metabolism of 5-lipoxygenase pathway leukotrienes by human eosinophils: predominant production of leukotriene $\mathrm{C}_{4}$ Proc Natl Acad Sci USA 1983;80:7626-7630.

15. Hodges MK, Weller PF, Gerard NP, Ackerman SJ, Drazen JM. Heterogeneity of leukotriene $\mathrm{C}_{4}$ production by eosinophils from asthmatic and from normal subjects. Am Rev Respir Dis 1988;138:799-804.

16. Cowburn AS, Holgate ST, Sampson AP. IL-5 increases expression of 5 lipoxygenase-activating protein and translocates 5-lipoxygenase to the nucleus in human blood eosinophils. J Immunol 1999;163:456-465.

17. Lewis RA, Austen KF, Soberman RJ. Leukotrienes and other products of the 5-lipoxygenase pathway: biochemistry and relation to pathobiology in human diseases. $N$ Engl J Med 1990;323:645-655.

18. Henderson WR Jr, Tang LO, Chu SJ, Tsao SM, Chiang GK, Jones F, Jonas M, Pae C, Wang H, Chi EY. A role for cysteinyl leukotrienes in airway remodeling in a mouse asthma model. Am J Respir Crit Care Med 2002;165:108-116.

19. Drazen JM. Leukotrienes as mediators of airway obstruction. Am J Respir Crit Care Med 1998;158:S193-S200.

20. Lam BK, $\mathrm{Xu} \mathrm{K}$, Atkins MB, Austen KF. Leukotriene $\mathrm{C}_{4}$ uses a probenecid-sensitive export carrier that does not recognize leuko-

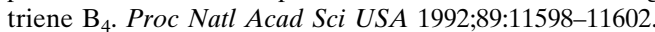

21. Kanaoka Y, Boyce JA. Cysteinyl leukotrienes and their receptors: cellular distribution and function in immune and inflammatory responses. J Immunol 2004;173:1503-1510.

22. Bandeira-Melo C, Bozza PT, Weller PF. The cellular biology of eosinophil eicosanoid formation and function. J Allergy Clin Immunol 2002;109: 393-400.

23. Peters-Golden M, Brock TG. Intracellular compartmentalization of leukotriene biosynthesis. Am J Respir Crit Care Med 2000;161:S36-S40.

24. Brock TG, Anderson JA, Fries FP, Peters-Golden M, Sporn PH. Decreased leukotriene $\mathrm{C}_{4}$ synthesis accompanies adherence-dependent nuclear import of 5-lipoxygenase in human blood eosinophils. J Immunol 1999;162:1669-1676.

25. Balestrieri B, Maekawa A, Xing W, Gelb MH, Katz HR, Arm JP. Group $\mathrm{V}$ secretory phospholipase A2 modulates phagosome maturation and regulates the innate immune response against Candida albicans. J Immunol 2009;182:4891-4898.

26. Bozza PT, Yu W, Penrose JF, Morgan ES, Dvorak AM, Weller PF. Eosinophil lipid bodies: specific, inducible intracellular sites for enhanced eicosanoid formation. $J$ Exp Med 1997;186:909-920.
27. Tauchi-Sato K, Ozeki S, Houjou T, Taguchi R, Fujimoto T. The surface of lipid droplets is a phospholipid monolayer with a unique fatty acid composition. J Biol Chem 2002;277:44507-44512.

28. Bozza PT, Magalhaes KG, Weller PF. Leukocyte lipid bodiesbiogenesis and functions in inflammation. Biochim Biophys Acta 2009;1791:540-551.

29. Martin S, Parton RG. Lipid droplets: a unified view of a dynamic organelle. Nat Rev Mol Cell Biol 2006;7:373-378.

30. Dvorak AM, Morgan E, Schleimer RP, Ryeom SW, Lichtenstein LM, Weller PF. Ultrastructural immunogold localization of prostaglandin endoperoxide synthase (cyclooxygenase) to non-membrane-bound cytoplasmic lipid bodies in human lung mast cells, alveolar macrophages, type II pneumocytes, and neutrophils. J Histochem Cytochem 1992;40:759-769.

31. Yu W, Bozza PT, Tzizik DM, Gray JP, Cassara J, Dvorak AM, Weller PF. Co-compartmentalization of MAP kinases and cytosolic phospholipase $\mathrm{A}_{2}$ at cytoplasmic arachidonate-rich lipid bodies. Am J Pathol 1998;152:759-769.

32. Bandeira-Melo C, Phoofolo M, Weller PF. Extranuclear lipid bodies, elicited by CCR3-mediated signaling pathways, are the sites of chemokine-enhanced leukotriene $\mathrm{C}_{4}$ production in eosinophils and basophils. J Biol Chem 2001;276:22779-22787.

33. Vieira-de-Abreu A, Assis EF, Gomes GS, Castro-Faria-Neto HC Weller PF, Bandeira-Melo C, Bozza PT. Allergic challenge-elicited lipid bodies compartmentalize in vivo leukotriene $\mathrm{C}_{4}$ synthesis within eosinophils. Am J Respir Cell Mol Biol 2005;33:254-261.

34. Beil WJ, Weller PF, Peppercorn MA, Galli SJ, Dvorak AM. Ultrastructural immunogold localization of subcellular sites of TNF-alpha in colonic Crohn's disease. J Leukoc Biol 1995;58:284-298.

35. Bozza PT, Yu W, Cassara J, Weller PF. Pathways for eosinophil lipid body induction: differing signal transduction in cells from normal and hypereosinophilic subjects. J Leukoc Biol 1998;64:563-569.

36. Vieira-de-Abreu A, Amendoeira FC, Gomes GS, Zanon C, Chedier LM, Figueiredo MR, Kaplan MA, Frutuoso VS, Castro-Faria-Neto $\mathrm{HC}$, Weller PF, et al. Anti-allergic properties of the bromeliaceae Nidularium procerum: inhibition of eosinophil activation and influx. Int Immunopharmacol 2005;5:1966-1974.

37. Mesquita-Santos FP, Vieira-de-Abreu A, Calheiros AS, Figueiredo IH, Castro-Faria-Neto HC, Weller PF, Bozza PT, Diaz BL, BandeiraMelo C. Cutting edge: prostaglandin $\mathrm{D}_{2}$ enhances leukotriene $\mathrm{C}_{4}$ synthesis by eosinophils during allergic inflammation: synergistic in vivo role of endogenous eotaxin. J Immunol 2006;176:1326-1330.

38. Bozza M, Satoskar AR, Lin G, Lu B, Humbles AA, Gerard C, David JR. Targeted disruption of migration inhibitory factor gene reveals its critical role in sepsis. $J$ Exp Med 1999;189:341-346.

39. Bandeira-Melo C, Sugiyama K, Woods LJ, Phoofolo M, Center DM, Cruikshank WW, Weller PF. IL-16 promotes leukotriene C(4) and IL-4 release from human eosinophils via CD4- and autocrine CCR3chemokine-mediated signaling. J Immunol 2002;168:4756-4763.

40. Leng L, Metz CN, Fang Y, Xu J, Donnelly S, Baugh J, Delohery T, Chen Y, Mitchell RA, Bucala R. MIF signal transduction initiated by binding to CD74. J Exp Med 2003;197:1467-1476.

41. Poltorak A, He X, Smirnova I, Liu MY, Van Huffel C, Du X, Birdwell D, Alejos E, Silva M, Galanos C, et al. Defective LPS signaling in $\mathrm{C} 3 \mathrm{H} / \mathrm{HeJ}$ and $\mathrm{C} 57 \mathrm{BL} / 10 \mathrm{ScCR}$ mice: mutations in Tlr4 gene. Science 1998;282:2085-2088.

42. Bernhagen J, Mitchell RA, Calandra T, Voelter W, Cerami A, Bucala R. Purification, bioactivity, and secondary structure analysis of mouse and human macrophage migration inhibitory factor (MIF). Biochemistry 1994;33:14144-14155.

43. Mitchell RA, Metz CN, Peng T, Bucala R. Sustained mitogen-activated protein kinase (MAPK) and cytoplasmic phospholipase A2 activation by macrophage migration inhibitory factor (MIF): regulatory role in cell proliferation and glucocorticoid action. J Biol Chem 1999;274: 18100-18106.

44. Bartemes KR, McKinney S, Gleich GJ, Kita H. Endogenous plateletactivating factor is critically involved in effector functions of eosinophils stimulated with IL-5 or IgG. J Immunol 1999;162: 2982-2989.

45. Bandeira-Melo C, Weller PF. Mechanisms of eosinophil cytokine release. Mem Inst Oswaldo Cruz 2005;100:73-81. 